INTERNATIONAL DESIGN CONFERENCE - DESIGN 2018

https://doi.org/10.21278/idc.2018.0372

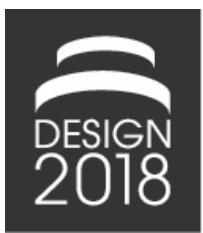

\title{
WORLDS APART AND CLOSE TOGETHER: RELATING MECHATRONICS AND PROJECT MANAGEMENT RESEARCH
}

\author{
E. Flening and A. Jerbrant
}

\begin{abstract}
While they originate from different contexts and values, the Mechatronic and Project Management research communities are both committed to the study of the process of complex engineering systems design. These two fields have generally been engaged in their research separated from each other. Recently, calls have been heard from both to end such disciplinary separation. This paper seeks to conceptually relate the two research communities, seeking to understand how they can be seen as different, related and inclusive of each other through offering three conceptual models of their relationships.
\end{abstract}

Keywords: design methodology, mechatronics, project management, conceptual models, multi-/cross-/trans-disciplinary approaches

\section{Introduction}

Understanding design, especially in the early conceptual phases, of products and systems has for a long time been the interest of diverse fields of research, each with different but often interacting ideas of what exactly that understanding is and how to arrive at it. The challenges of conceptual engineering design of systems are multi-dimensional, of technical (Tomiyama et al., 2007), cognitive (Howard et al., 2008), and social natures (Hodgson et al., 2011; Cross, 2013; Mørkeberg Torry-Smith et al., 2013; Greene et al., 2017). This is also true for research that develops knowledge about these challenges. Many research fields are engaged, e.g. engineering to management to social and cognitive psychology, and need to be. There need to be cross-disciplinary research between communities, to gain needed additional perspectives on both multi- and inter-dimensional challenges. Previous endeavours into understanding ways-of-thinking in different research streams (e.g. Greene et al., 2017), motivate further exploration of the conceptual spaces between research communities.

Two such research communities are the engineering design field of mechatronic product development and that of project management (PM). Both are engaged in investigating aspects of design, as well as being related to each other. Projects became a visible (and viable) area for research during the fifties for similar reasons as for mechatronics in the seventies: increasing complexity. In the first case it was increasing complexity of governance for organizational endeavours including more and more (kinds of) people as well as knowledge. In the second case it was the increasing complexity of multi-disciplinary technical systems arising from ever-increasing demands of system performance, which in turn also necessitated more and more (kinds of) people and knowledge. One of the more recent PM-publications (Geraldi and Söderlund, 2016) focused on how PM research trends emphasize that the fundamental contribution of PM-research is the production and reproduction of researchers. And that research as a community must have the capability to develop reflexive and engaged scholars that can perform engaged research within project studies. 
This article will discuss these two research communities and how they conceptually relate to each other, with the aim of laying down conceptual groundwork to support the difficulty of intimately working across research fields that have very different languages and norms. As such, this is a conceptual and initial paper intended for further work. This paper refer to the mechatronic research community, and it should be stated that the scope and borders of such a community are hazy at best, as it is with all of engineering design research (Blessing and Chakrabarti, 2009, p. 4). For the project management research community, some PM researchers recognize that theory for practice are social processes with a technical core (Geraldi and Söderlund, 2016). As such, both communities overlap and interact with many other connected communities and disciplines, amongst others Systems Engineering (SE) (Bradley, 2010; Hehenberger and Bradley, 2016), cyberphysical systems (Guerineau et al., 2016; Ragavan and Shanmugavel, 2017), and engineering design (e.g. Eppinger and Salminen, 2001).

The paper is structured as followed: Sections 2 and 3 introduce relevant literature from the two research communities using four themes: history, values, applications, and methods. Using these themes, Section 4 suggests three conceptual models, visually comparing project management and mechatronics. Section 5 concludes the paper with some suggestions for future research. None of the three models are "right" or "wrong", since context determines which model might be the more fruitful one for understanding the focal research problem. What is intended is for the proposed conceptual models to stimulate crossdisciplinary discussion, primarily between the project and mechatronics communities. We welcome disagreement and intend for this work to dispel discursive silence.

\section{Mechatronics}

\subsection{The history of mechatronics research}

Non-linear technological development was a defining feature of the $20^{\text {th }}$ century, and a central driver for change. One of these changes was the emergence of mechatronics, coined by Tetsuro Mori of Yaskawa Electric Corporation in 1969: It described mechanical systems (mecha-) that were then being increasingly introduced to more precise control, implemented through electronic (-tronics!) motors, sensors and control circuits, than what was previously possible through mostly mechanical designs (Auslander, 1996; Tomizuka, 2002; Hehenberger and Bradley, 2016). This pushed mechanical and electronic engineers to work more tightly together and striving to understand each other's languages

(Hehenberger and Bradley, 2016, p. 17). This is not to say that technical integration began with mechatronics, as Bradley (2010) points out. Mechatronics refers rather to technical integration that is situated in an historical and engineering-domain context: how mechanical and electronic engineering became increasingly integrated from the seventies onward.

The integration and common-language efforts became more demanding when software (computer science engineering) went from a supporting role (e.g. as a tool for mechatronic system development) in the late 1980s and 1990, to taking increasing responsibility for real-time system decision making (Auslander, 1996). At the turn of the millennium it was thought that IT would play an increasingly significant role in mechatronics (Tomizuka, 2002). An illustrative example of how this came to be can be seen in the historically important development process model for mechatronic systems, the V-model (Mooz and Forsberg, 2006).

The V-model is common when introducing mechatronic systems development to students and newcomers, and it emphasizes two core concepts for mechatronics: First, the decomposition of the system into (often functional or discipline-specific) subsystems and the subsequent integration of these into the realized system; Second, the planning of how to integrate, verify and validate the system at all system-levels. The goal of the model is to enable concurrent engineering, where all the subsystems are developed in parallel (Mooz and Forsberg, 2006). What is interesting is that the V-model were not specifically developed or intended for mechatronic, but for systems development, coming from software development. Conceptually, this clashes with the domain-legacy of mechatronics, which still maintains mechanical engineering as its founder-domain: many university programs in mechatronics came from mechanical engineering-related departments.

This means that not only is a mechatronic system inextricably constituted by physical parts and processes that demand very different kinds of knowledge to understand them, but the tools and models 
used to view both whole and parts of the system are historically situated in different traditions of knowledge. This is still true today.

\subsection{Values - what is important for mechatronics research?}

Central to the mechatronics research community has been a desire for conceptual and methodological unity in mechatronic system design theory and practice (Buur, 1990; Auslander, 1996; Tomizuka, 2002; Habib, 2006; Zheng et al., 2014; Ragavan and Shanmugavel, 2017), with statement like the following being common: " Building a system-level model, in a unified unambiguous language, is a key point for a successful mechatronic design."'(Mhenni et al., 2014). But, like in most design research traditions, this has been found to be a Sisyphean task: the boulder of technological advancement is always rolling. As can be seen in their discussion on the challenges in designing mechatronic systems when Mørkeberg Torry-Smith et al. (2013) state that "Most papers about mechatronic design end by stating that a common methodology and a common conceptual model is needed. This statement has been repeated for the last $20 \mathrm{yr}$. If it was possible, it would have been likely that such a method would have been found, or significant findings presented which would be a step toward it."

This is not to say that methodological (i.e. system development methods and processes) research in mechatronics is futile, quite the opposite: it is mechatronics research bread-and-butter. But it is always ongoing, never finished, since the object of any proposed method will be subject to the same technological advancement (e.g. Gausemeier et al., 2009).

We can never remove our way of thinking, working or conceptualizing from contemporary technological frames (Orlikowski and Gash, 1994; Orlikowski and Scott, 2008; Thakker et al., 2011), but we can mitigate them through another core value for mechatronics: seeking effective communication and a common language. The urgent call for the focus on such soft issues as crucial for the multi-disciplinary collaboration necessitated by mechatronic systems development were present at the founding of mechatronics (Salminen and Verho, 1989; Buur, 1990, pp. 26-27), and has not weakened over the years (Bradley, 2010; Mørkeberg Torry-Smith et al., 2013; Torry-Smith et al., 2014; Zheng et al., 2014, 2017; Guerineau et al., 2016; Hehenberger and Bradley, 2016; Westman and Nyberg, 2016). So mechatronics knows what it needs, but like most engineering fields its fundamentally rationalistic engineering values predisposes it towards ways of thinking and reasoning that has made it historically ill-disposed to deal with the details of these soft problems in a non-superficial way (e.g. Greene et al., 2017). "Soft concepts" strongly linked to communication and understanding, e.g. trust (Mellinger, 1956; Porta et al., 1997; Jarvenpaa and Leidner, 1999; Tanis and Postmes, 2005), are rarely brought up when dealing with issues of communication and common understanding. Hillmer's (2009) work on technology acceptance in mechatronics systems development organizations, which takes trust and social psychology as central, is an exception.

Emergence is another important value for the mechatronics community, and for the engineering design research community in general. Originally this applied specifically to the emergence of technical functionality from integrated systems of disciplinary-disparate technological parts. It has travelled upwards in abstraction with time, and could now be said to influence not only how the product-system is seen, but also the process by which it is created, as well as the organization that houses that process (Eppinger and Salminen, 2001; Zheng et al., 2014).

\subsection{Applications - where does mechatronics research happen?}

When Steinbuch (in Hehenberger and Bradley, 2016, p. 19) recently reviewed the literature he found that "more application papers are submitted on medical devices, on high precision systems, drones (UAV), automotive and robotics." and that it seems like fewer papers have been submitted on "modelling languages and tools" as well as on mechatronics education, which was a "hot topic in the late 1990s".

These three can be seen as application categories of mechatronics research that have fluctuated over time: Mechatronics education, Specific technology application research, and systems development process research (SDP). It is this last stream of research within mechatronics that is the most relevant for this article, in that it has most in common with the project management field in terms of the aims and topics for research: Both aim to understand and/or improve actual work-processes for system design and have process models as common topics. As Hollauer and Lindemann states in (Chakrabarti and Chakrabarti, 2017, p. 610): “[Engineering Design Processes] are generally regarded as being knowledge-intensive and 
different from regular business processes: They are dynamic, creative and often chaotic with iterations and jumps, lacking overall predictability." The development process-side of mechatronics research is closely related to engineering design research, as well as SE and model-based SE (MBSE), and many times mechatronics is used as the context for a case study for some development model, rather than as the focus for that model. In the SDP area many process models exist (Mørkeberg Torry-Smith et al., 2013; Zheng et al., 2014; Hehenberger and Bradley, 2016). Most of these, like the V-model, were not exclusively developed for mechatronic system development. In fact, one could position mechatronic system development process models as a part of a wider family of Design and Development Process (DDP) models, as described by Wynn and Clarkson (2017) in their comprehensive organizing framework of DDP models. Even though their framework does not hold mechatronics as central in itself, the same fundamental concerns central to DDP models - which are novelty in the design object, iteration and complexity in the design process (Wynn and Clarkson, 2017, pp. 161-162) - also hold as central for mechatronic SDP. These three concerns relate directly to the values discussed in the previous section.

\subsection{Research methods in mechatronics}

One could, maybe somewhat uncharitably, say that mechatronics as a research field has an implicit methodology tradition, if by "method" we mean the chain of thinking leading from: problem/questionstatement; to the description of its context; to how it has been addressed before (or not); to how it might be fruitfully addressed now, which includes a discussion and selection of tools for studying said problem. That is, "method" refers to both the tools and the process of the research effort, not to any potential development method the paper might have as it's unit of analysis.

It is not so much that mechatronics research lacks method, more that it often does not discuss method further than saying "this is how we did it". This "lack of scientific rigour" is an overarching phenomenon in design research (Blessing and Chakrabarti, 2009), and not unique to engineering design or mechatronics system design research, SDP or otherwise.

Research method preferences of empirical mechatronics SDP research could generally be said to include: Literature surveys, often around SDP models; Structured or semi-structured interviews with practitioners, specialist engineers, project managers, system architects, and other project stakeholders; Observations of design teams and their members; Case studies, most often used as illustrative examples of how some proposed process model might be used, showcasing the strengths of the model. Case studies are less often used as a method for inductive empirical investigation and exploration in this kind of SDP research.

The format for a SDP paper is usually the following: "We have problem X with mechatronic systems development, and these previous solutions have been proposed but lacking in important ways, primarily A, $\mathrm{B}$, and C (obviously more/fewer are possible). Our solution $\mathrm{Y}$ addresses these weaknesses through the Zmodel that recognizes the influence and dynamics of $\mathrm{A}, \mathrm{B}$, and $\mathrm{C}$ on the development process. This is how $\mathrm{Z}$ is structured and intended to be implemented, although sufficient tailoring must be addressed for any single instance of $Z$. Finally, here is a case study of how $Z$ could be implemented in a mechatronic systems development project." Some examples of this line of reasoning can be found in (Cao et al., 2011; Mørkeberg Torry-Smith et al., 2013; Mhenni et al., 2014; Hehenberger and Bradley, 2016; Zheng et al., 2016, 2017). The format described above as normative reflects some potential practical implications of the rationalistic engineering values, discussed above in Section 2.2, on how the shape of empirical research method has developed in SDP.

\section{Project management}

\subsection{A historical view on projects and project management}

Projects have been executed throughout the world for hundreds of years. In the 15th to 17th century planners and executors of large projects relied increasingly on the emerging concepts of engineering science and emphasized the importance of delivering on time. Artto et al. (2011) describes these kind of projects as "large technical and commercial projects involving contractual systems between parties" with a strong focus on problem solving and a focus to be more efficient by collaborating in networks of companies. After this came projects that related more to technical development, for instance the development of the telegraph and telephone system (Artto et al., 2011) and then the focus laid on 
emphasizing planning by engineers and contractual deliveries, but in the 1950 s a more scientific and methodological approach emerged. This decade is today considered the beginning of modern PM, due to the publications (e.g. Gaddis, 1959) describing a more systematic way of managing projects, at the same time as industry began to develop techniques for this (the focus of Systems Engineering). The development of management methods and tools for supporting the execution of projects have been strong since the 1950s. During this period project management methods and techniques were mastered by engineers with a focus on cost estimates, prototype design, operating methods, supply chain management, contract negotiations (Garel, 2013). But after this, in the 1970s and the 1980s the focus changed towards a more team-centred approach and research focused on how the actions of the project teams as well as the project manager influenced project success. In the 1980s computerized tools and follow up methods were developed and the projects where modelled as larger entities, paralleling the emergence of mechatronics and its increasing inclusion of IT and computer science (Artto et al., 2011). Research on project management has developed a great deal since the 1990s, becoming more of an organizational mode and a system of anticipating and rationalizing temporary collective initiatives during 2000 (Garel, 2013). But in 2006 the Rethinking PM network called for a paradigm shift in project research and proposes five research directions. The directions inspired research and marked a milestone in the development of the field (Winter et al., 2006).

\subsection{Values and applications in project management research}

Traditional project management is often presented (in for instance PMBOK) as a set of normative procedures that is imposed to result in successful projects if they are followed (Williams, 2005). But many studies have showed that even if the PM procedures are used the promised benefits is not achieved, and some researchers even claim that in big, complex and speedy projects traditional project management is simply counterproductive (Koskela and Howell, 2002). This since some of the underlying assumptions of project management is that PM is rational with a main concern to manage scope, which leads to a heavy emphasize to planning as well as a decoupling from the environment (Williams, 2005). Conventional PM methods are heavily based on the "management-as-planning" principle (Williams, 2005). But if a project is complex it might be difficult to understand intuitively how the project results is dependent of causal feedback and non-linear behaviour (which also might cause effects that are visible after significant time-delays). But project complexity can be defined in two different ways (Williams, 2005); (1) structural complexity (made up of the size or number of elements in the project) and the interdependence between these elements and (2) uncertainty both in formulating and identifying the project goals as well as how to achieve these goals. Williams (2005) therefore emphasize that project behaviour most often is complex and counterintuitive and it's when uncertainty affects a traditionally managed project that is structurally complex that you need systemic modelling focus.

But the rational planning-view within project management research allows us to emphasize goal realization, i.e. the form of the project work, and has a normative purpose, focusing on efficiency, sequential planning and goal achievement. Morris (1997) describes project management as essentially consisting of: "integrating all that needs doing for the project to be a success; the project's evolution through its lifecycle; using a number of tools, techniques, practices and concepts, some of which are special to project management; procurement and integration of external resources; working together on a team basis" (1997). Packendorff (1995, p. 328) describes how this kind of project management research is characterized by a normative focus on methods comparing time plans and budgets, as well as results. Therefore, the methods that are emphasized mainly provides guidelines for how the project management should focus on how to structure and plan the project and how to ensure that planned activities are performed in the right order (Engwall et al., 2003, p. 113).

Research based on the rational planning-view includes PM research focused on processes. PM knowledge areas also becomes important. Both project-based firms and international project management associations have established their own project management guidelines (Artto et al., 2011; Garel, 2013) with a distinct expression of which knowledge areas and processes that project management has to incorporate; for instance scope management, integration management, schedule management, cost management, risk management, quality management etc. But as a complement to the perspective of the PM knowledge areas and processes, PM can also be focused on which competences 
that are needed. For example the knowledge, skills, attitudes and characteristics that the people doing projects should have as well as the behaviours that are needed for project success (Artto et al., 2011). Having a process focus in PM research puts the main focus on decision-making models.

An important criticism of PM research that has a rational planning-view is that it does not discuss important aspects like renewal and uncertainty (Lundin and Söderholm, 1995, p. 452), since projects primarily are seen as a way of executing a predefined assignment.

So, analysis shows that conventional, traditional, PM methods can be in-appropriate and potentially disadvantageous for projects that are structurally complex, uncertain and heavily time-limited (Williams, 2005). The emergence of project management research based on a view emphasizing Projects as a complex system with organizational dependencies has been strong since the mid-1990s, especially in Scandinavia, and has involved both a large number of in-depth studies of projects and the use of new theoretical approaches (e.g. Sahlin-Andersson and Söderholm, 2002; Söderlund, 2004, 2005).

The Scandinavian School of Project Studies developed an understanding of projects primarily by combining an organization theory perspective, with theories on entrepreneurship and industrial development, with in-depth empirical studies of how projects unfold in practice (Sahlin-Andersson and Söderholm, 2002, p. 11). From the complex system-view, executing a project means increasing our knowledge of something unknown, and therefore different aspects need to be modified during its implementation. In addition, there are several participants in a project, which according to Andersen (2010) means that "a project does not necessarily speak with one voice, and not all steps are governed centrally". Thus, the fact that projects are designed, defined and established with the help of different actors' more or less conscious actions (Engwall et al., 2003) are enhanced: "Understanding projects as socially constructed, organizationally embedded, and open structures with a natural ingredient of uncertainty directs our attention to issues outside the traditional agenda of project management research." (Engwall et al., 2003).

Packendorff (1995) discusses the difference between viewing projects as rational methods and models (rational planning-view) on the one hand, and as temporary organization on the other hand (complex systems-view) in more detail. He defines a temporary organization as an organized and collective act aimed at developing a non-routine process and producing a non-routine product. Viewing projects like this gives the organization a predetermined time limit when it ceases to exist (with some performance and evaluation criteria), and emphasizes its complexity in terms of roles and group dynamic (Packendorff, 1995). What needs to be studied in this kind of project management research is how to create an understanding of the temporary organizational processes: the conscious social interaction that occurs between people working together to handle a specific predetermined task and fulfil the development of a product (Packendorff, 1995).

This PM research has more of a descriptive purpose, and views the organization as constituting people in social interaction, looking for both similarities and differences (without focus on generalizability), thinks that the description of reality is intersubjective (i.e. socially created and dependent on perspective) and highlights the importance of understanding that we are studying different actors that experience the same practice in different ways.

All of this illustrates the development of project management research, that at first had a rational planning theory perspective, with an initial focus of a general practical application to the understanding that project management methods must be adapted to context, the number of included elements and the technical core of the project assignment. Projects and project management should therefore not be seen as an unambiguous term, but rather as a family of concepts, and therefore it does not make sense to stipulate one, once and for all, unambiguous and universal definition of what a project is.

\subsection{Research methods in project management}

So, even though projects often are defined as unique assignments with a predefined goal that needs to be fulfilled within a certain time-frame, budget and specifications, three types of project research can be identified (Geraldi and Söderlund, 2016). The first type is pragmatic research focused on project processes, and this research tends to be focused on prediction and control, executed as positivistic science. Type two research perceives projects as unique opportunities to address, with a focus to contribute to particular theoretical questions in organization theory and general management. The 
scholars conducting type three research are engaged in investigating project practice and the context. In order to understand the "realities" and challenges of the profession of PM. However, these scholars are aware of, and engaged with academic conversations outside project studies as well as the ones within their community. When executing type 2 and 3 research the research methods are often interpretative and hermeneutic (and sometimes critical social sciences).

\section{Concept models}

Considering the four themes used to describe PM and SDP research above, some comparisons and contrasting viewpoints will be presented through three conceptual models. Each model represents a different possible viewpoint of the conceptual relationship between PM and SDP. This approach has been previously used to explore the conceptual space between different ways-of-thinking in design (Greene et al., 2017), and has inspired the structure for the conceptual models below.

The first model starts from a distinctive perspective of PM and SDP and the four themes, understanding them as two separate entities with different origins and values that are oriented towards investigating different phenomena. The second takes a more overlapping approach to how PM and SDP can be understood, seeing emergence as a common perspective taken when researching both projects and mechatronic systems development processes as phenomena. The third conceptual model takes on a more inclusive form, seeing project management as part of mechatronic SDP research (project management (in some of its forms) being a necessary component for most SDPs) and also in terms of how the common values around language and understanding relates PM as inclusive inside SDP.

\subsection{Separate concept model}

One way to relate PM research with mechatronic SDP research is to view them as separate conceptual entities with distinct characteristics and origins. Mechatronics originated in mechanical engineering and as previously stated, mechatronics research in general seeks to develop state-of-the-art SDP and unifying research efforts are understood to be a desired characteristic, although not presently being the case, or by some even believed possible (Torry-smith et al., 2011), it is still a perceived as desirable. Project management research, on the other hand, thrives in its own fractured nature. Apart from some fundamental perspectives, the project management research community is conceptually disparate, with research being done both with an organizing, action-oriented, temporarily focus as well as with a planning, goal and decision-making focus.

Fundamental methodological perspectives are also distinct aspects of SDP and PM, such as assumptions in SDPs of rational behaviour amongst stakeholders, or how the Scandinavian School views projects as permeable and socially-constructed organizational structures, while SDP take a rationalistic-technical view of system-focused development methods that put emphasis on functional investigation of explicit interactions in the system concepts (this is the area of system architectural design).
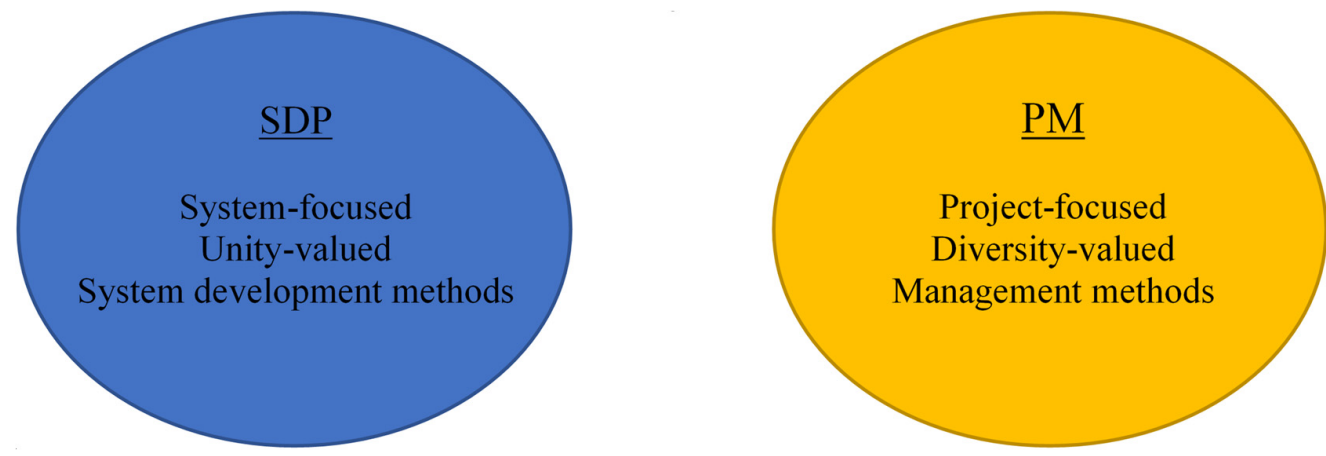

Figure 1. Separate concept model

\subsection{Comparative concept model}

A more comparative concept model can also be argued for when relating PM to SDP, in that there are important areas where the two overlaps and share conceptual perspectives, while maintaining their 
distinctiveness in other. When understanding the two fields as overlapping but separate entities, emergence as a value comes forward as common ground in that holistic features and properties of heterogenous complex systems are seen as important and desired. For mechatronics in general, technological emergence of system properties are even definitional: if a system does not have emergent features, it is not a mechatronic system. This has also become the case for non-technological emergence as a perspective for mechatronics research in general, not only SDP, and here it overlaps with PM.

Process-focus and level of inquiry are two other conceptual overlaps between SDP and PM, at least as it concerns rational-planning-PM research which has a process-focus and an orientation towards individual/team-level. When it comes to research methods, both overlap and divergence exist in the comparative model, especially regarding the use of interviews and observations in empirical studies, which both fields make heavy use of when conducting empirical research. The divergence lies in how these methods are more structured and systems-centred for SDP. In PM research, these are less structured and more emergent, with a more human-centred approach. In the Scandinavian school, methods are often less empirically oriented, and more focused on critical theory and interpretations of text using hermeneutics and other reflexive methodologies (Alvesson and Sköldberg, 2009; Geraldi and Söderlund, 2016).

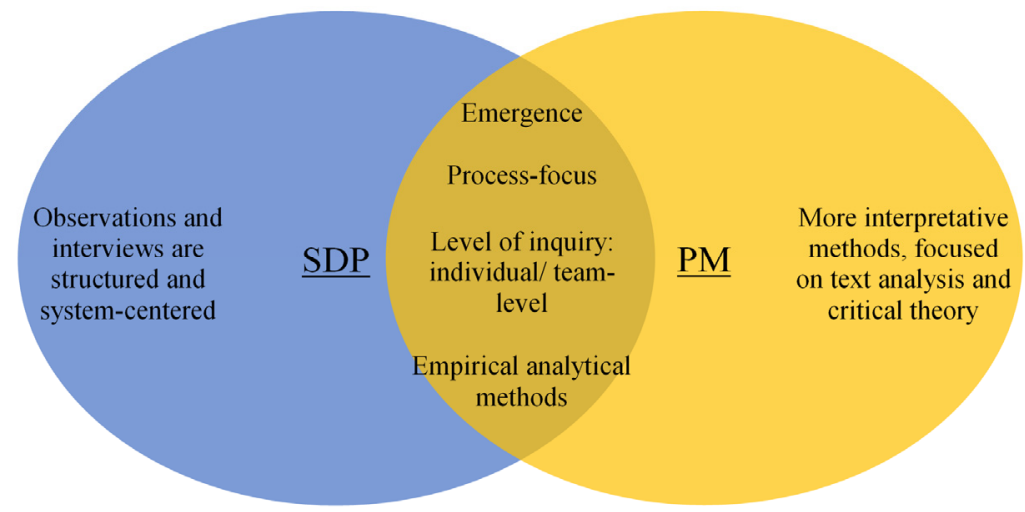

Figure 2. Comparative concept model

\subsection{Inclusive concept model}

The third conceptual model takes on an inclusive form, seeing project management as part of mechatronic SDP research. First, in the sense that project management needs a context to be empirically visible: it cannot exist without a referent. In this model, mechatronic SDP research have PM as a necessary process-component, while at the same time serving as a context for PM. So, here we can see two ways in which the model is inclusive of PM inside of SDP: SDP-as-context-for-PM and PM-ascomponent-in-SDP. Second, both fields hold a strong common value in that common language and mutual cross-disciplinary understanding in (mechatronic systems development) projects are vital avenues for research and desirable goals in and of themselves both in research and in practice for both disciplines. A parallel development can be seen in the Object-Process Methodology (OPM) of Sharon and Dori (Sharon et al., 2011; Sharon and Dori, 2012, 2015) where efforts have been made to "integrate the project with the product", bridging the fields of PM and SE by developing shared ontologies (in their Product Life-cycle Management framework) and concrete modelling tools (such as OPCAT, an implementation of OPM) for supporting project planning. SDP-research, and mechatronics research in general, is more disposed towards inquiring into the more technical aspects of language/understanding, in terms of (for example) standards (e.g. ISO15288:2015), technical system viewpoint contracts (Westman and Nyberg, 2016), scientific notation, or cross-disciplinary data management (Zheng et al., 2017). When it comes to more human-centred perspectives around this issue - such as intrapersonal communication, trust, team-culture, handling social ambiguity, cognitive psychology, and group dynamics - PM comes to the fore. Here PM and SDP can benefit from each other, PM from SDP-ascontext as above, and SDP from the additional human-centred perspective on understanding and language that PM has. 


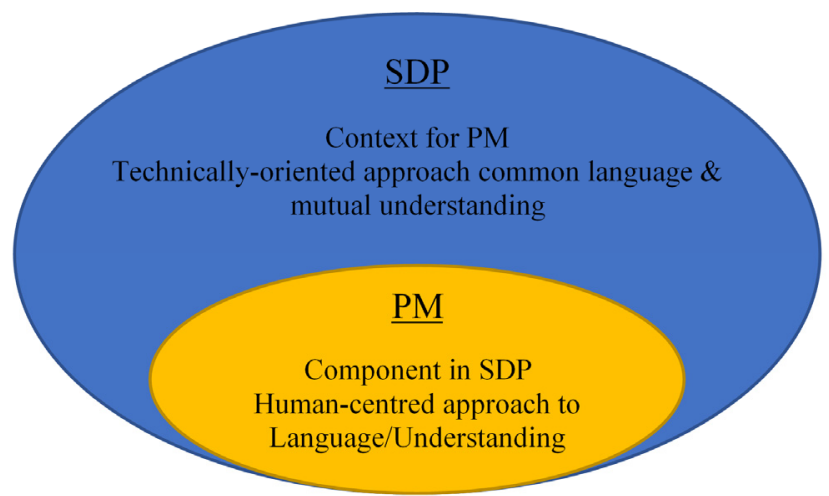

Figure 3. Inclusive concept model

\section{Conclusion and future research}

The fields of project management and mechatronics are tightly linked and, at the same time, worlds apart. Both aim to build knowledge around some aspect of design (i.e. system design/project design), and depending how one chooses to see them, they are either close (e.g. how rational-planning-PM and SDP are goal-oriented) or far away from each other (e.g. unity vs. diversity). As presented in the introduction, this work has discussed how the two research communities, PM and SDP, view their research and each other differently. The conceptual models above display three ways for understanding these differences, the first best explaining how they are very different, the second how they have some common ground, and with the third (inclusive) model being the more useful view for understanding how mechatronic SDP are researched. This has been the main contribution of this paper.

The purpose here was not to make a comprehensive literature review and analysis nor to refine definitions of either fields, but rather to lay the conceptual groundwork for future research relating project management to mechatronic SDP, both in research and (later) in practice. Any researcher wanting to explore complex product development projects needs to recognize that they are studying an essential social process with an intricate technical core. As such, further research is required to make a more focused analysis of the complexities in and between PM and SDP, for the purpose of developing a detailed understanding of their relationship. For instance, this could take the form of an exploratory case study into a single organization that uses mechatronic SDPs and PM, to investigate this relationship in practice.

\section{References}

Alvesson, M. and Sköldberg, K. (2009), Reflexive Methodology, 2nd ed., SAGE Publications.

Andersen, E.S. (2010), "Rethinking Project Management - An Organisational Perspective", Strategic Direction, Vol. 26 No. 3. https://doi.org/10.1108/sd.2010.05626cae.001

Artto, K., Martinsuo, M. and Kujala, J. (2011), Project Business, Helsinki.

Auslander, D.M. (1996), "What is mechatronics?", IEEE/ASME Transactions on Mechatronics, Vol. 1 No. 1, pp. 5-9. https://doi.org/10.1109/3516.491404

Blessing, L.T.M. and Chakrabarti, A. (2009), DRM, a Design Research Methodology, Springer, London. https://doi.org/10.1007/978-1-84882-587-1

Bradley, D. (2010), "Mechatronics - More questions than answers", Mechatronics, Vol. 20 No. 8, pp. 827-841. https://doi.org/10.1016/j.mechatronics.2010.07.011

Buur, J. (1990), A Theoretical Approach to Mechatronics Design, Institute for Engineering Design, APA.

Cao, Y., Liu, Y. and Paredis, C.J.J. (2011), "System-level model integration of design and simulation for mechatronic systems based on SysML", Mechatronics, Vol. 21 No. 6, pp. 1063-1075. https://doi.org/10.1016/j.mechatronics.2011.05.003

Chakrabarti, A. and Chakrabarti, D. (2017), Research into Design for Communities, Vol. 2, Springer, Singapore. https://doi.org/10.1007/978-981-10-3521-0

Cross, N. (2013), Designerly Ways of Knowing, Springer-Verlag, London. 
Engwall, M., Steinthórsson, S. and Söderholm, A. (2003), “Temporary organizing: A Viking approach to project management research", In: Czarniawska-Joerges, B. and Sevón, G. (Eds.), The Northern Lights: Organization Theory in Scandinavia, Liber, pp. 111-130.

Eppinger, S.D. and Salminen, V. (2001), "Patterns of Product Development Interactions", 13th International Conference on Engineering Design, ICED01, pp. 283-290.

Gaddis, P.O. (1959), The Project Manager, Harvard University, Boston.

Garel, G. (2013), "A history of project management models: From pre-models to the standard models", International Journal of Project Management, Vol. 31 No. 5, pp. 663-669. https://doi.org/10.1016/j.ijproman.2012.12.011

Gausemeier, J., Frank, U., Donoth, J. and Kahl, S. (2009), "Specification technique for the description of selfoptimizing mechatronic systems", Research in Engineering Design, Vol. 20 No. 4, pp. $201-223$. https://doi.org/10.1007/s00163-008-0058-x

Geraldi, J. and Söderlund, J. (2016), "Project studies and engaged scholarship”, International Journal of Managing Projects in Business, Vol. 9 No. 4, pp. 767-797. https://doi.org/10.1108/IJMPB-02-2016-0016

Greene, M., Gonzalez, R., Papalambros, P. and McGowan, A.-M. (2017), "Design thinking VS. Systems thinking for engineering design: What's the difference?", Proceedings of ICED'17 / the 21st International Conference on Engineering Design, Vancouver, Canada, August 21-25, 2017, The Design Society, Glasgow, pp. 467-476.

Guerineau, B., Bricogne, M., Durupt, A. and Rivest, L. (2016), "Mechatronics vs. cyber physical systems: Towards a conceptual framework for a suitable design methodology", 11th France-Japan \& 9th Europe-Asia Congress on Mechatronics (MECATRONICS) / 17th International Conference on Research and Education in Mechatronics (REM), pp. 314-320. https://doi.org/10.1109/MECATRONICS.2016.7547161

Habib, M.K. (2006), "Mechatronics engineering the evolution, the needs and the challenges", IECON Proceedings (Industrial Electronics Conference), IEEE, pp. 4510-4515. https://doi.org/10.1109/IECON.2006.347925

Hehenberger, P. and Bradley, D. (2016), Mechatronic Futures: Challenges and Solutions for Mechatronic Systems and Their Designers, Springer, Cham. https://doi.org/10.1007/978-3-319-32156-1

Hillmer, U. (2009), Technology Acceptance in Mechatronics: The Influence of Identity on Technology Acceptance, Gabler. https://doi.org/10.1007/978-3-8349-8375-6

Hodgson, D., Paton, S. and Cicmil, S. (2011), "Great expectations and hard times: The paradoxical experience of the engineer as project manager”, International Journal of Project Management, Vol. 29 No. 4, pp. 374-382. https://doi.org/10.1016/j.ijproman.2011.01.005

Howard, T.J., Culley, S.J. and Dekoninck, E. (2008), "Describing the creative design process by the integration of engineering design and cognitive psychology literature", Design Studies, Vol. 29 No. 2, pp. 160-180. https://doi.org/10.1016/j.destud.2008.01.001

Jarvenpaa, S.L. and Leidner, D.E. (1999), “Communication and Trust in Global Virtual Teams”, Organization Science, Vol. 10 No. 6, pp. 791-815. https://doi.org/10.1287/orsc.10.6.791

Koskela, L.J. and Howell G. (2002), "The underlying theory of project management is obsolete", Proceedings of the PMI Research Conference, PMI.

Lundin, R.A. and Söderholm, A. (1995), "A theory of the temporary organization”, Scandinavian Journal of Management, Vol. 11 No. 4, pp. 437-455. https://doi.org/10.1016/0956-5221(95)00036-U

Mellinger, G. (1956), "Interpersonal trust as a factor in communication", Journal of Abnormal and Social Psychology, Vol. 52 No. 3, pp. 304-309. https://doi.org/10.1037/h0048100

Mhenni, F., Choley, J.Y., Penas, O., Plateaux, R. and Hammadi, M. (2014), “A SysML-based methodology for mechatronic systems architectural design", Advanced Engineering Informatics, Vol. 28 No. 3, pp. $218-231$. https://doi.org/10.1016/j.aei.2014.03.006

Mooz, H. and Forsberg, K. (2006), "The dual vee - Illuminating the management of complexity", 16th Annual International Symposium of the International Council on Systems Engineering, INCOSE 2006, Vol. 2, pp. 1368-1381. https://doi.org/10.1002/j.2334-5837.2006.tb02819.x

Mørkeberg Torry-Smith, J., Qamar, A., Achiche, S., Wikander, J., Henrik Mortensen, N. and During, C. (2013), "Challenges in designing mechatronic systems", Journal of Mechanical Design, Vol. 135 No. 1, pp. 1-11. https://doi.org/10.1115/1.4007929

Morris, P.W.G. (1997), The Management of Projects, T. Telford.

Orlikowski, W.J. and Gash, D.C. (1994), "Technological frames: making sense of information technology in organizations", ACM Transactions on Information Systems, Vol. 12 No. 2, pp. 174-207. https://doi.org/10.1145/196734.196745

Orlikowski, W.J. and Scott, S.V. (2008), "Sociomateriality: Challenging the Separation of Technology, Work and Organization", The Academy of Management Annals, Vol. 2 No. 1, pp. 433-474. https://doi.org/10.1080/19416520802211644 
Packendorff, J. (1995), "Inquiring into the temporary organization: New directions for project management research", Scandinavian Journal of Management, Vol. 11 No. 4, pp. 319-333. https://doi.org/10.1016/09565221(95)00018-Q

Porta, R.L., Lopez-de-silanes, F., Shleifer, A. and Vishny, R.W. (1997), “Trust in Large Organizations”, American Economic Review Papers and Proceedings, Vol. 87 No. 2, pp. 333-338. https://doi.org/10.1126/science.151.3712.867-a

Ragavan, S.K.V. and Shanmugavel, M. (2017), "Engineering cyber-physical systems-Mechatronics wine in new bottles?", 2016 IEEE International Conference on Computational Intelligence and Computing Research, ICCIC 2016, IEEE, pp. 1-5. https://doi.org/10.1109/ICCIC.2016.7919516

Sahlin-Andersson, K. and Söderholm, A. (2002), Beyond Project Management: New Perspectives on the Temporary - Permanent Dilemma, Liber.

Salminen, V. and Verho, A.J. (1989), "Multi-Disciplinary Design Problems in Mechatronics and Some Suggestions to its Methodical Solution in Conceptual Design Phase", International Conference on Engineering Design (ICED89), Vol. 1, pp. 533-554.

Sharon, A. and Dori, D. (2012), "Integrating the project with the product for applied systems engineering management”, IFAC Proceedings Volumes (IFAC-PapersOnline), Vol. 14 No. 1, pp. 1153-1158. https://doi.org/10.3182/20120523-3-RO-2023.00366

Sharon, A. and Dori, D. (2015), "A project-product model-based approach to planning work breakdown structures of complex system projects", IEEE Systems Journal, Vol. 9 No. 2, pp. 366-376. https://doi.org/10.1109/JSYST.2013.2297491.

Sharon, A., De Weck, O.L. and Dori, D. (2011), "Project management vs. systems engineering management: A practitioners' view on integrating the project and product domains", Systems Engineering, Vol. 14 No. 4, pp. 427-440. https://doi.org/10.1002/sys.20187

Söderlund, J. (2004), "Building theories of project management: Past research, questions for the future", International Journal of Project Management, Vol. 22 No. 3, pp. 183-191. https://doi.org/10.1016/S02637863(03)00070-X

Söderlund, J. (2005), Projektledning Och Projektkompetens - Perspektiv På Konkurrenskraft, Liber.

Tanis, M. and Postmes, T. (2005), "Short communication a social identity approach to trust: Interpersonal perception, group membership and trusting behaviour", European Journal of Social Psychology, Vol. 35 No. 3, pp. 413-424. https://doi.org/10.1002/ejsp.256

Thakker, D., Yang-Turner, F., Lau, L. and Dimitrova, V. (2011), "Socio-technical ontology development for modelling sensemaking in heterogeneous domains", CEUR Workshop Proceedings, Vol. 809, pp. 60-71. https://doi.org/10.1016/j.intcom.2010.07.003

Tomiyama, T., D’Amelio, V., Urbanic, J. and Eimaraghy, W. (2007), "Complexity of multi-disciplinary design", CIRP Annals - Manufacturing Technology, Vol. $56 \quad$ No. 1, pp. 185-188. https://doi.org/10.1016/j.cirp.2007.05.044

Tomizuka, M. (2002), "Mechatronics: From the 20th to 21st century", Control Engineering Practice, Vol. 10 No. 8, pp. 877-886. https://doi.org/10.1016/S0967-0661(02)00016-3

Torry-Smith, J.M., Achiche, S., Mortensen, N.H., Qamar, A., Wikander, J. and During, C. (2011), "Mechatronic design - Still a considerable challenge", ASME 2011 International Design Engineering Technical Conferences \& Computers and Information in Engineering Conference, pp. 1-12. https://doi.org/10.1115/DETC201148306

Torry-Smith, J.M., Mortensen, N.H. and Achiche, S. (2014), “A proposal for a classification of product-related dependencies in development of mechatronic products", Research in Engineering Design, Vol. 25 No. 1, pp. 53-74. https://doi.org/10.1007/s00163-013-0161-5

Westman, J. and Nyberg, M. (2016), "Conditions of Contracts for Separating Responsibilities in Heterogeneous Systems", Formal Methods in System Design, Vol. 52. No. 2, pp. 147-192. https://doi.org/10.1007/s10703017-0294-7

Williams, T. (2005), "Assessing and moving on from the dominant project management discourse in the light of project overruns", IEEE Transactions on Engineering Management, Vol. 52 No. 5, pp. 497-508. https://doi.org/10.1109/TEM.2005.856572

Winter, M., Smith, C., Morris, P. and Cicmil, S. (2006), "Directions for future research in project management: The main findings of a UK government-funded research network", International Journal of Project Management, Vol. 24 No. 8, pp. 638-649. https://doi.org/10.1016/j.ijproman.2006.08.009

Wynn, D.C. and Clarkson, P.J. (2017), "Process models in design and development", Research in Engineering Design, Vol. 29 No. 2, pp. 161-202. https://doi.org/10.1007/s00163-017-0262-7

Zheng, C., Bricogne, M., Le Duigou, J. and Eynard, B. (2014), "Survey on mechatronic engineering: A focus on design methods and product models", Advanced Engineering Informatics, Vol. 28 No. 3, pp. $241-257$. https://doi.org/10.1016/j.aei.2014.05.003 
Zheng, C., Hehenberger, P., Le Duigou, J., Bricogne, M. and Eynard, B. (2017), "Multidisciplinary design methodology for mechatronic systems based on interface model", Research in Engineering Design, Vol. 28 No. 3, pp. 333-356. https://doi.org/10.1007/s00163-016-0243-2

Zheng, C., Le Duigou, J., Bricogne, M. and Eynard, B. (2016), "Multidisciplinary interface model for design of mechatronic systems", Computers in Industry, Vol. 76, pp. 24-37. https://doi.org/10.1016/j.compind.2015.12.002

Elias Flening, PhD Student

KTH Royal Institute of Technology, Department for Machine Design

Fatburs Kvarngata 9, 11864 Stockholm, Sweden

Email: flening@kth.se 